\title{
Numerical and experimental study of the Behaviour of notched HDPE
}

\author{
Rabiaa Elkori ${ }^{1}{ }^{\mathrm{a}}$, Amal Laamarti ${ }^{1}{ }^{\mathrm{b}}$, Khalid Elhad $^{2} \mathbb{C}^{\mathrm{c}}$ Abdelilah Hachim ${ }^{1} \mathbb{C}^{\mathrm{d}}$ \\ ${ }^{1}$ Hassan II University, National Higher School of Electricity and Mechanics, El Jadida Street, km 7, BP: 8118, Oasis, \\ Casablanca, Morocco \\ ${ }^{2}$ Higher Institute of Maritims Studies, Casablanca, Morocco \\ \{Rabiaaelkori,abdelilah.hachim\}@gmail.com,Lamarti.amal18@gmail.com
}

Keywords: PEHD, tensile test, U notch, V notch, Behaviour.

Abstract: It is important to study the Behaviour of high-density polyethylene (HDPE) under notch effects as it is widely used in industrial applications (Qi, 2018). However, there are only a few studies on the Behaviour of HDPE with defects, this work aims to study the deformation mechanisms under a tensile test experimentally performed on blank and notched specimens at constant speed and room temperature, and by developing our study by simulating HDPE using commercial software code.

a (Dhttps://orcid.org/0000-0000-0000-0000
b (D)https://orcid.org/0000-0000-0000-0000
c (D)https://orcid.org/0000-0000-0000-0000

diDhttps://orcid.org/0000-0000-0000-0000 


\section{INTRODUCTION}

High density of polyethylene "HDPE" is widely used in industrial applications Because of its lightness, durability, flexibility and its impact resistance, e.g. bottles of HDPE cooling (Qi, 2018). Industrial packaging and other applications (Ngoc Giang, 2015) takes into consideration the effects of defects, which have changed the Behaviour of HDPE from ductile to brittle. In this work we will present numerical simulation using the finite element method to study numerically the Behaviour of HDPE under a uniaxial tensile test and in particular the measurement of stresses and strains. The uniaxial tensile tests consist in exerting a displacement in the transverse direction of one side of the specimen, the specimen used is of the parallelepiped type for the three tests (blank, V notch, $U$ notch).In a second step, the experimental results obtained with the MTS series 40 traction machine and the TWE MTS control software will be compared with the numerical results.

\section{BEHAVIOUR LAW}

- The experimental tests are carried out at room temperature of $23 \mathrm{c} \square \quad$ and at constant stress speed. The Young's Modulus of $\mathrm{HDPE}$ is $\mathrm{E}=1153 \mathrm{Mpa}$ and the Poisson's ratio $v=0.4$.

- The specimen used for the numerical and the experimental tests is of the parallelepiped type.

- The U shaped notch is $5 \mathrm{~mm}$ deep and $5 \mathrm{~mm}$ wide.

- The V-shaped notch has a depth of $5 \mathrm{~mm}$ and an opening of $5 \mathrm{~mm}$.

- The following table summarizes the dimensions of the specimen.

Table 1:Dimensions of specimens used in experimental tests.

\begin{tabular}{|l|l|l|l|}
\hline $\begin{array}{l}\text { Test tube } \\
\text { parallelepiped }\end{array}$ & $\begin{array}{l}\text { Length } \\
(\mathrm{mm})\end{array}$ & $\begin{array}{l}\text { Width } \\
(\mathrm{mm})\end{array}$ & $\begin{array}{l}\text { Thickness } \\
(\mathrm{mm})\end{array}$ \\
\hline Blank & 100 & 20 & 1.10 \\
\hline With U notch & 100 & 20 & 1.10 \\
\hline With V notch & 100 & 20 & 1.10 \\
\hline
\end{tabular}

- We carried out the same numerical tests under the same working conditions.

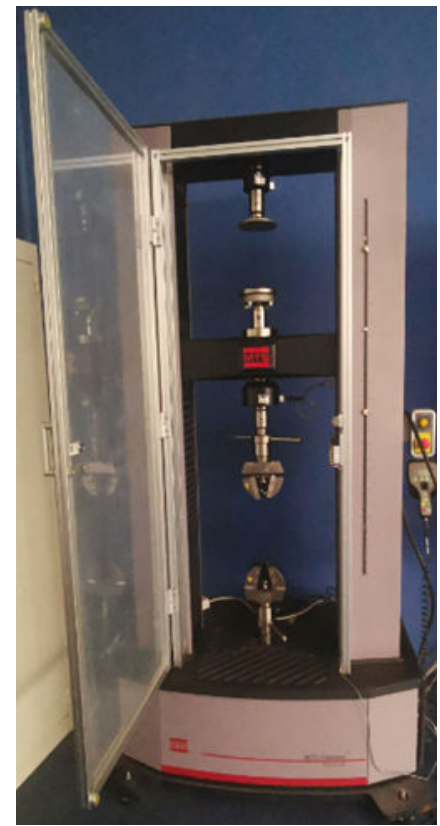

Figure 1: MTS series 40 machine used in the experimental test.

\subsection{Blank test tube}

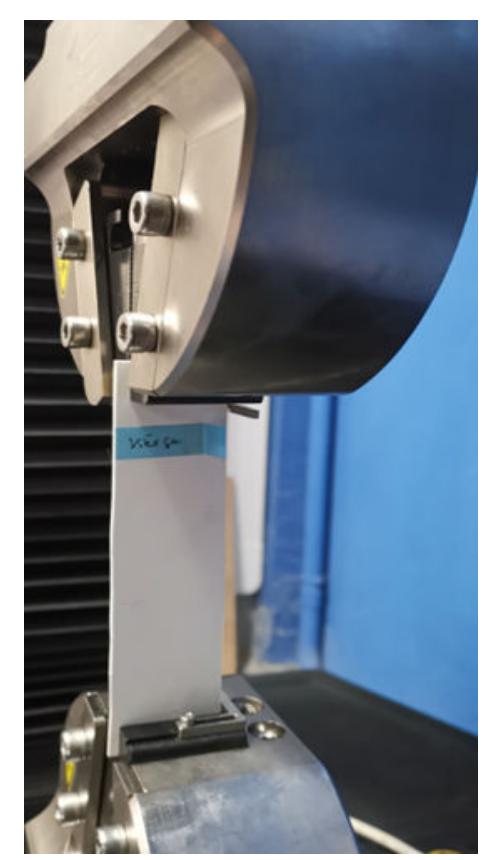

Figure 2:Experimental blank test tube. 


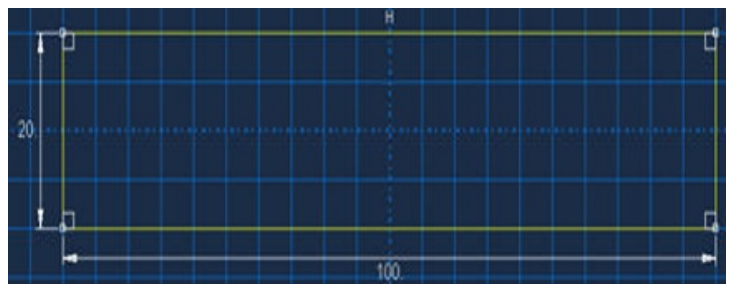

Figure 3:Making the specimen on commercial software.

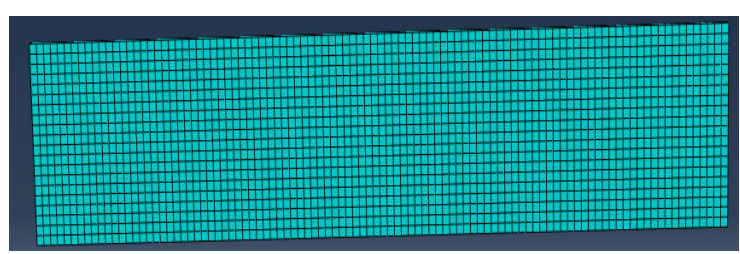

Figure 4:Mesh used in the numerical test.

\subsection{Test specimen with $V$ notch}

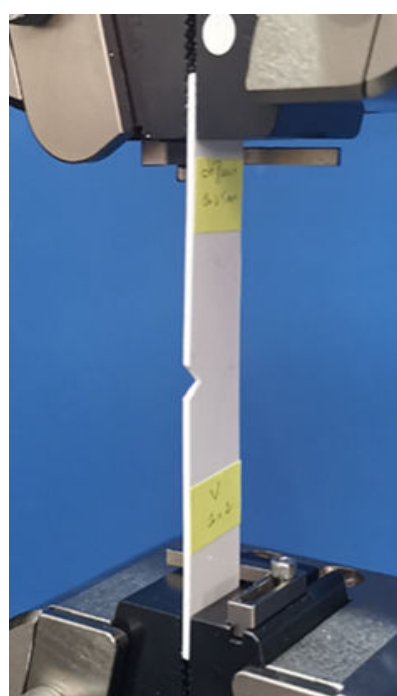

Figure 5:Experimental test tube.

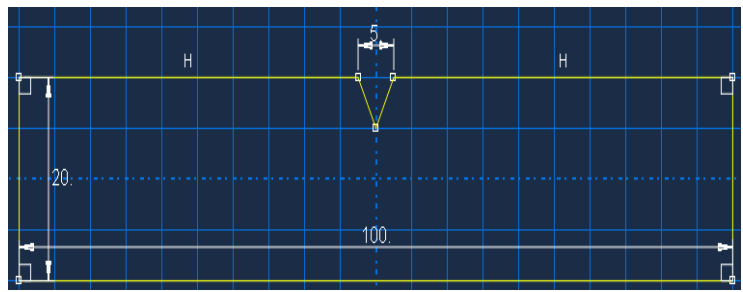

Figure 6: Making the notch specimen $\mathrm{V}$ on commercial software.

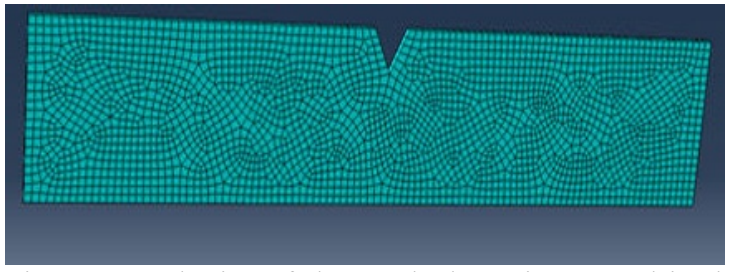

Figure 7:Mesh size of the notched specimen used in the numerical test.

\subsection{Testspecimen with $U$ notch}

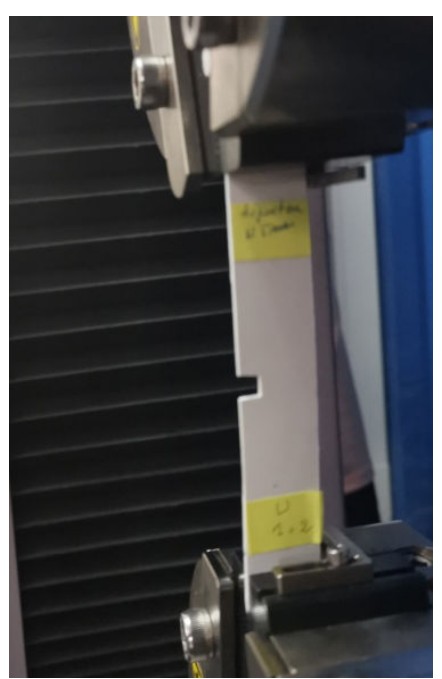

Figure 8: Experimental test tube.

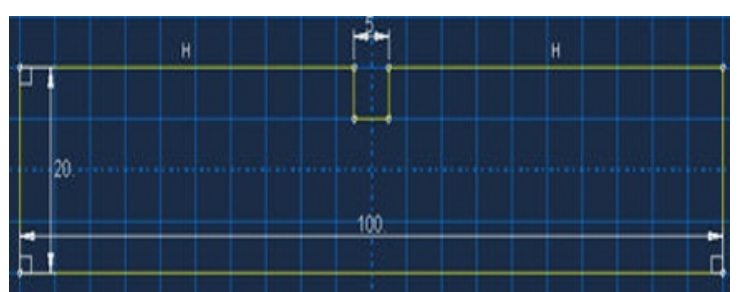

Figure 9: Making the notch specimen $U$ on commercial software.

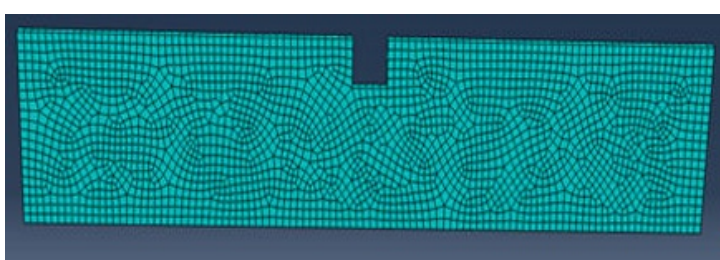

Figure 10: Mesh used in the numerical test.

\section{RESULTS}


- The following figure shows the numerical and the experimental results of the HDPE characterization curve:

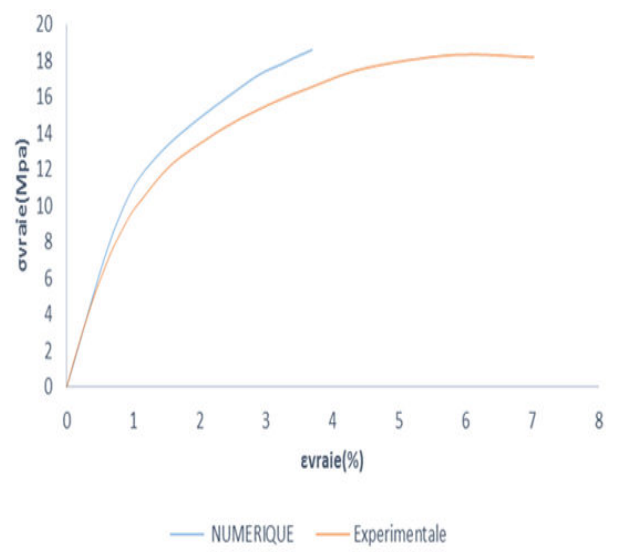

Figure 11: The numerical and experimental true stressstrain curve.

- The numerical and experimental curve of the characterization test evolves in the same way, the elastic part of the two curves aremerged, after there is a shift in the plastic zone (after a displacement of the plastic zone), we notice that the maximum stress calculated numerically is approximate to the one calculated experimentally.

- Figure 12 shows the numerical and the experimental results of the HDPE specimen with $\mathrm{V}$ notch of $5 \mathrm{~mm}$ depth and $5 \mathrm{~mm}$ aperture.

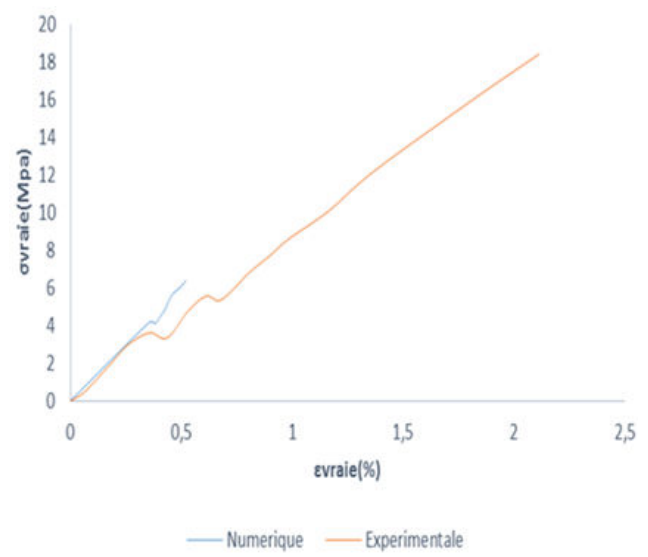

Figure 12:Numerical and experimental true stress-strain notch curve $\mathrm{v}$.
- The elastic zone of the numerical and the experimental curve agree, the evolution of the zone of plastic instability of the two curves is the same, the experimental curve has a wider range of strain and stress compared to the numerical curve.

- The following figure is a representation of the numerical and experimental results of the HDPE specimen in the presence of the U notch with a $5 \mathrm{~mm}$ opening and $5 \mathrm{~mm}$ depth.

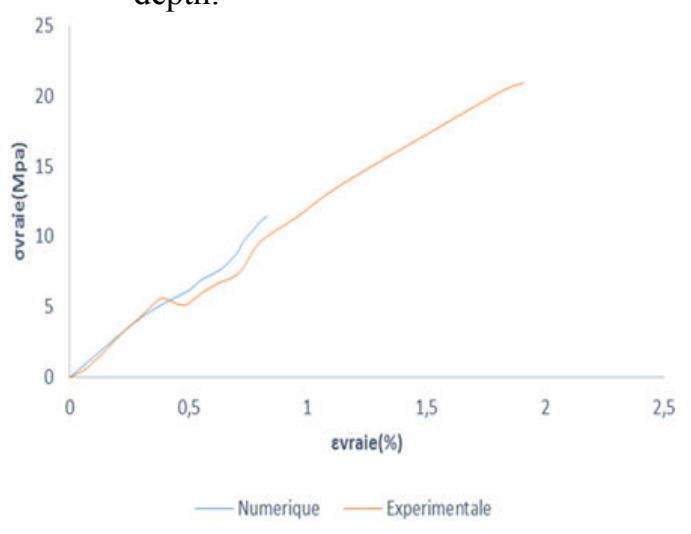

Figure 13:True stress-strain curve of the notched specimen U.

- The numerically calculated elastic limit is greater than the elastic limit calculated in the experiment, the elastic part is the same evolution. The numerical maximum stress is small compared to the experimental stress.

\section{CONCLUSIONS}

In this work, a numerical study is was carried out using Abaqus simulation software based on the finite element method, and an experimental study is carried out to better understand the Behaviour of HDPE in its virgin state and under the effects of notches. The comparison between the numerical and experimental results shows the great difference in the results obtained in the presence of notched defects, the reason can be classified as Fracture strain and Damage evolution, which are not sufficiently accurate at the numerical calculation level, but the results obtained in the characterization tests are strongly consistent.

\section{REFERENCES}

TRAN, N. G. ( 2015). Etude expérimentale et numérique de l'influence des interactions contenant/contenu sur le comportement 
élastoviscoplastique d'emballages en

polyéthylène haute densité. ARDENNE:

UNIVERSITE DE REIMS CHAMPAGNE.

Zhengpan Qi, N. H. (2018). Constitutive Modeling for the Elastic-viscoplastic Behavior of High Density Polyethylene under. International Journal of Plasticity, 45. 